\title{
A PERCEPÇÃO DOS DOCENTES DO CURSO DE EDUCAÇÃO FÍSICA EM RELAÇÃO ÀS CONTRIBUIÇÕES DO PIBID NA FORMAÇÃO DOS ACADÊMICOS BOLSISTAS DO SUBPROJETO EDUCAÇÃO FÍSICA ${ }^{1}$
}

\author{
Janaina Andretta Dieder \\ Instituição Evangélica de Novo Hamburgo, Novo Hamburgo, Rio Grande do Sul, Brasil \\ Luis Eurico Kerber \\ Universidade Feevale, Novo Hamburgo, Rio Grande do Sul, Brasil \\ Katia Ternus \\ Universidade Feevale, Novo Hamburgo, Rio Grande do Sul, Brasil
}

\begin{abstract}
Resumo
O estudo busca investigar a percepção dos professores do curso de Licenciatura em Educação Física da Universidade Feevale (Rio Grande do Sul) em relação ao desenvolvimento acadêmico dos bolsistas do subprojeto PIBID Educação Física, inseridos no programa de 2012 a 2014. Adota o delineamento de um estudo qualitativo descritivo. O instrumento empregado para a coleta de dados foi a entrevista semiestruturada, contando com a participação de seis docentes. Ficou evidente, na percepção dos docentes participantes do estudo, a relevância do programa no meio acadêmico, o qual incentiva a docência e possibilita uma formação diferenciada para os bolsistas através da articulação entre teoria e prática, impactando no gosto ou não pela docência, bem como na mudança de comportamento de acadêmicos após o ingresso no programa.
\end{abstract}

Palavras-chave: Educação Física. Formação continuada. Docência.

\section{Introdução}

A atividade docente está cada vez mais complexa, exigindo uma visão contextualizada e interdisciplinar. De acordo com Libâneo (2011, p.12), "o professor precisaria, no mínimo, de uma cultura geral mais ampliada, capacidade de aprender a aprender, competência para saber agir na sala de aula". Portanto, cada momento no exercício da docência é oportuno para refletir sobre questões educacionais, tornando-se uma prática mediadora da produção do conhecimento e suas experiências enquanto professor.

Em vista disso, entende-se como necessária uma formação docente que abarque não somente o aspecto teórico, mas também questões práticas. Sob esse prisma, Gadotti (2003) afirma que a formação do professor não deve ser concebida apenas como a aprendizagem de novas técnicas, mas sim envolver constante reflexão, pesquisa, ação, descoberta, organização, fundamentação, revisão e construção teórica.

Apesar da importância da prática na formação docente, tradicionalmente ela é considerada simplesmente como um espaço de aplicação da teoria, sendo essa uma concepção reducionista. Ressalta-se que a prática é muito mais do que isso, pois é um recinto de

\footnotetext{
${ }^{1}$ Financiamento: Programa Institucional de Bolsa de Iniciação à Docência - PIBID 
produção, de transformação e de mobilização de saberes, ou seja, de teorias e conhecimentos. É através dela que o professor utiliza, mobiliza e produz os saberes de seu trabalho, que "não é simples nem previsível, mas complexo e enormemente influenciado pelas próprias decisões e ações desse ator" (TARDIF, 2012, p.236). Desse modo, toda a experiência acumulada pelo professor torna-se uma bagagem importante, que será utilizada em todos os momentos de sua atuação.

De acordo com Kleiman (2001), o debate acerca da formação de professores tem mobilizado não somente os profissionais da educação, mas também o poder público, visto que existe uma estreita relação entre sucesso/fracasso escolar e formação de professores. A partir disso, percebe-se o PIBID (Programa Institucional de Bolsa de Iniciação à Docência) como resultado dessas discussões, sendo uma ação conjunta do Ministério da Educação, por intermédio da Coordenação de Aperfeiçoamento de Pessoal de Nível Superior (CAPES).

O PIBID foi instituído pelo decreto $\mathrm{n}^{\circ} 7.219$, de 24 de junho de 2010, e indica, em seu artigo $1^{\circ}$, que é executado no âmbito da CAPES e tem por finalidade fomentar a iniciação à docência, contribuindo para o aperfeiçoamento da formação de docentes em nível superior e para a melhoria de qualidade da educação básica pública brasileira (BRASIL, 2010).

Sobre este Programa, podem-se evidenciar os apontamentos de Pimenta (2004): surge como alternativa para qualificar o estudante que está em processo de aprendizagem na universidade, pois é durante a formação inicial que as vivências têm um papel fundamental como ponto de partida do conhecimento. O MEC aponta, nas Políticas Públicas para Educação, a formação de professores como sendo um tema crucial, pois os desafios colocados à escola exigem do trabalho educativo outro patamar profissional, muito superior ao hoje existente (BRASIL, 1999).

Nesse sentido, dentre os objetivos do PIBID, destacam-se como principais, no que tange à formação dos acadêmicos bolsistas: incentivar a formação de docentes em nível superior para a educação básica; elevar a qualidade da formação inicial de professores nos cursos de licenciatura, promovendo a integração entre educação superior e educação básica; inserir os licenciandos no cotidiano de escolas da rede pública de educação, proporcionandolhes oportunidades de criação e participação em experiências metodológicas, tecnológicas e práticas docentes de caráter inovador e interdisciplinar que busquem a superação de problemas identificados no processo de ensino-aprendizagem; e contribuir para a articulação entre teoria e prática necessárias à formação dos docentes, elevando a qualidade das ações acadêmicas nos cursos de licenciatura (BRASIL, 2010).

André (2012) ressalta, ainda, que os programas desenvolvidos em parceria entre universidade e escola constituem-se como alternativas para superar o distanciamento que se analisa ao longo da história entre os recintos de formação e do exercício profissional. António Nóvoa, já em 1997, afirmava a importância do desenvolvimento desses programas de iniciação à docência por parte das instituições de ensino, buscando aproximar os acadêmicos do ambiente escolar e as situações de ensino, aplicando o conhecimento obtido e adquirindo outros (NÓVOA, 1997). Além disso, destacou que tais programas ajudam os estudantes a se identificarem com a profissão e beneficiam a inserção na docência.

O PIBID, além de conceder bolsas para os acadêmicos e docentes das universidades, presta um auxílio financeiro também aos professores das escolas públicas que acompanham as atividades dos bolsistas no espaço escolar, "atuando assim como coformadores no processo de iniciação à docência, em articulação com o formador da universidade" (ANDRÉ, 2012, p.125). O programa teve início em 2007 e ampliou-se rapidamente, abrangendo, em 2011, universidades públicas estaduais, municipais e comunitárias em todas as licenciaturas. No primeiro semestre de 2014, atingiu mais de 70 mil bolsas para acadêmicos em 284 Instituições de Nível Superior participantes, conforme fontes do site da CAPES (2014). 
Apesar de ainda não existirem avaliações abarcantes sobre o PIBID, o estudo de André (2012) tem demonstrado resultados muito positivos, destacando-se: motivação dos bolsistas para ingressar na profissão e disposição dos professores das escolas, que, ao reverem suas práticas através dos bolsistas, sentem-se desafiados (ANDRÉ, 2012). Isso nos remete à formação continuada, quando o profissional da educação estará, de certa forma, acompanhando a evolução do mundo e dos conhecimentos que necessitam ser trabalhados com os alunos, bem como adquirindo novas ideias e compartilhando experiências com os futuros professores (TARDIF, 2012).

Na Universidade Feevale, localizada na cidade de Novo Hamburgo (RS), o PIBID teve início em 9 de setembro de 2010, tendo como principais objetivos, de acordo com Reichert, Meinhardt e Lima (2014, p.8):

\begin{abstract}
Aproximar ainda mais teoria e prática, a partir da socialização das experiências dos alunos bolsistas vivenciadas no PIBID, nas salas de aula da universidade, em seminários específicos ou a partir da apresentação de trabalhos, beneficiando um maior número de alunos com as experiências do PIBID; Promover o desenvolvimento do senso crítico, do espírito investigativo, da criatividade, a partir do contato com as escolas e a oportunidade de colocar em prática os conhecimentos construídos ao longo do curso.
\end{abstract}

Analisando os estudos de alguns autores (PAREDES, 2012; REICHERT; MEINHARDT; LIMA, 2014), podemos afirmar que o PIBID, na Universidade Feevale e em todo país, vem se destacando, demonstrando, a partir de políticas públicas, a valorização da formação docente e dos cursos de licenciatura, bem como da qualidade na educação que, nessa perspectiva, na dimensão prática, não se reduz a momentos isolados, previsto no percurso formativo das licenciaturas como práticas de ensino ou estágios curriculares.

Para buscar uma iniciação à docência de caráter teórico-prático, através da aproximação entre universidade e escolas de Educação Básica, o PIBID vai além das dimensões conceituais e procedimentais, do saber e saber fazer, almejando-se um futuro professor que atinja, também, a dimensão atitudinal, ou seja, um professor que compreenda aquilo que faz através de uma prática docente reflexiva (REICHERT; MEINHARDT; LIMA, 2014). A partir disso, o presente artigo tem como objetivo investigar a percepção dos professores da instituição de ensino superior Universidade Feevale, do curso de Licenciatura em Educação Física, em relação ao desenvolvimento acadêmico dos bolsistas do subprojeto PIBID Educação Física nos anos de 2012 a 2014.

\title{
Processo metodológico
}

O presente estudo deu-se por meio de uma pesquisa qualitativa descritiva, adotando o procedimento metodológico de um estudo de caso na perspectiva qualitativa, pois tem como objetivo investigar a percepção dos professores da instituição de ensino superior Universidade Feevale, do curso de Licenciatura em Educação Física, em relação ao desenvolvimento acadêmico dos bolsistas do subprojeto PIBID Educação Física nos anos de 2012 a 2014.

A pesquisa teve como contexto investigativo a Universidade Feevale, instituição sem fins lucrativos, que atua em todos os níveis de formação, localizada em Novo Hamburgo, Rio Grande do Sul (RS). Os sujeitos do estudo foram os docentes de Licenciatura em Educação Física da Universidade Feevale no ano de 2014, totalizando seis professores, sendo quatro do sexo masculino e dois do sexo feminino. Os colaboradores possuem idade entre 34 e 43 anos e tempo de atuação no ensino superior de 6 a 17 anos. O critério de seleção para a escolha dos participantes foi intencional, incluindo os docentes que lecionaram disciplinas específicas relacionadas à cultura corporal de movimento e saúde do escolar do curso de Educação Física, 
na modalidade licenciatura, em diferentes semestres, ampliando o tempo de contato e conhecimento dos acadêmicos bolsistas do PIBID, bem como no acompanhamento da caminhada acadêmica dos mesmos. Desses docentes, um deles já tinha sido coordenador do subprojeto Educação Física durante quatro anos, outro atua como gestor de processos educacionais e os demais não possuem vínculo direto com o Programa.

$\mathrm{O}$ instrumento de coleta de dados deste estudo consistiu em entrevista semiestruturada (NEGRINE, 2004), constituindo-se em cinco perguntas, sendo elas: 1) Como você percebe os resultados do PIBID na formação profissional e acadêmica dos bolsistas? 2) você percebe alterações na postura dos bolsistas como acadêmicos, considerando responsabilidade e participação em aula, discussões, produção escrita com aprofundamento teórico e domínio do processo de pesquisa, envolvimento em atividades extraclasse, entre outros? 3) Como você percebe a relação do PIBID com a busca, produção e construção de conhecimento teóricoprático dos acadêmicos bolsistas? 4) Pedagogicamente, há uma mudança na maneira dos bolsistas pensarem/planejarem e aplicarem suas ideias em sala de aula nas disciplinas cursadas com você? 5) Percebe diferenças entre o perfil dos acadêmicos bolsistas e não bolsistas? Comente. As entrevistas, com duração média de 30 minutos, foram realizadas individualmente, uma única vez com cada professor, na Universidade Feevale, gravadas e transcritas e, após a transcrição, o conteúdo foi validado pelos docentes.

O presente estudo não foi submetido ao Comitê de ética por não se enquadrar nas normas do Comitê da Instituição conforme Resolução da Reitoria Nº 03/2013 (FEEVALE, 2013). Entretanto, seguindo as orientações do CEP (Comitê de Ética em Pesquisa Universidade Feevale), foram observados aspectos quanto à privacidade, anonimato e uso totalmente científico, detalhados no Termo de Consentimento Livre e Esclarecido (TCLE), assinado pelos docentes (autorizando a publicação das informações), que está de acordo com a resolução 466/12 do CNS/MS Sobre Diretrizes e Normas Regulamentadoras de Pesquisa envolvendo seres humanos (BRASIL, 2012).

Para a análise das informações coletadas, foi adotada a proposta de análise de conteúdo de Bardin (2011), seguindo o percurso determinado: pré-análise, exploração do material e tratamento dos resultados. Sendo assim, foram definidas categorias, com base nas unidades de significados provenientes da leitura e destaque do discurso/entrevistas, com os quais, posteriormente, realizou-se a inferência e interpretação. Para a interpretação dos dados, utilizou-se a triangulação teórica e reflexiva, considerando-se teorias alternativas para interpretar os dados coletados, ou seja, a partir dos comentários mais relevantes dos docentes entrevistados foram realizadas as devidas ligações com os teóricos estudados (CAUDURO, 2004).

\section{Apresentação e discussão dos dados}

A partir do processo de análise dos dados coletados, foram constituídas duas categorias, sendo elas: a visão dos docentes com relação à influência do PIBID na formação profissional dos acadêmicos inseridos no programa; a percepção dos docentes com relação ao perfil dos acadêmicos em sala de aula no curso de Licenciatura em Educação Física.

Analisando-se a primeira categoria, ou seja, a visão dos docentes com relação à influência do PIBID na formação profissional dos acadêmicos inseridos no programa, pode-se sinalizar, nas respostas, os aspectos positivos destacados pelos colaboradores do estudo, como se pode perceber nos relatos dos docentes 01 e 05 com relação à visão do PIBID: "No meu ponto de vista, aproxima os alunos à realidade da escola, ao cotidiano da escola e já construindo um padrão de trabalho diferente do que vem acontecendo nos últimos anos" (Docente 01 - 16/12/2014). "Acho que o resultado do PIBID é importante no sentido que o 
acadêmico bolsista ele está buscando uma formação ampliada e principalmente porque esse programa é de aperfeiçoamento na docência" (Docente 05 - 19/12/2014).

Refletindo junto aos achados de Tardif (2012) quanto às falas dos professores 01 e 05, reafirma-se a necessidade dessa aproximação entre os saberes iniciais e as práticas cotidianas nas vivências e experiências do professor, para que, dessa forma, haja uma constante transformação da identidade do docente e ele possa analisar, avaliar e ressignificar sua prática, construindo um padrão de trabalho diferente, como aponta o docente 01. Corroborando ao mencionado, pode-se evidenciar os apontamentos de Borges (2003) sobre os saberes que são adquiridos através da caminhada profissional, que provêm de várias maneiras, desde a formação inicial (quando o PIBID pode estar inserido), contexto de trabalho e formação continuada. Entretanto, para que haja uma transformação, o professor precisa estar disposto e aberto às constantes e necessárias mudanças, principalmente quando existe uma troca coletiva de informações e experiências, que é o caso do Programa.

Ao abordar a importância do convívio no cotidiano escolar para a formação acadêmica destacada na fala anterior do docente 01 , o docente 06 enfatiza, no trecho de sua entrevista, que "O PIBID permite então que os alunos possam experimentar ali, na prática, uma série de questões que eles veem nos cursos de graduação" (Docente 06 - 18/12/2014). Contribuindo com isso, o Docente 04 (18/12/2014) afirma que o PIBID

[...] é um projeto de extrema importância, principalmente no que diz respeito a essa articulação teoria e prática. É uma possibilidade de o acadêmico estar dentro da universidade, estar estudando e percebendo a função teórica sobre alguns autores e estar colocando tudo isso em prática.

Nesse sentido, André (2012) e Nóvoa (1997) ressaltam que os programas desenvolvidos em parcerias entre universidades e escolas buscam aproximar os acadêmicos do ambiente escolar e das situações de ensino, aplicando o conhecimento obtido e adquirindo outros. Portanto, o Programa vem ao encontro dos discursos teóricos e dados empíricos trazidos nas entrevistas dos professores para o aprimoramento da docência.

Em vista disso, Pimenta (2004) aponta que o programa surge como alternativa para qualificar o estudante que está em processo de aprendizagem na universidade, pois é durante a formação inicial que as vivências têm um papel fundamental como ponto de partida do conhecimento. Nesse sentido, o professor 02 menciona, em sua entrevista, a difícil realidade que o acadêmico está sujeito a encontrar ao iniciar sua prática docente e que, apesar da sua falta de experiência, não é impedido de atuar:

[...] a proposta do PIBID ela é excelente em termos dessa imersão que é proporcionada ao acadêmico de vivenciar, de aprimorar suas atribuições pedagógicas, todo o processo de planejamento, avaliação, estruturação de planos, entender as realidades do contexto, tudo isso é extremamente significativo (Docente $02-16 / 12 / 2014)$.

Essa imersão do acadêmico licenciado no cotidiano da escola, referida pelo professor 02, contribui para a construção de um momento significativo na caminhada acadêmica, quando o mesmo tem oportunidades de compreender a realidade escolar, pois, de acordo com Brasil (2010), ele se submeterá aos reais problemas do dia-a-dia de uma escola pública, tendo que lidar com os conflitos de aluno/professor, levando, então, à articulação entre a teoria e prática necessárias para formação dos docentes.

Analisando a segunda categoria, a percepção dos docentes com relação ao perfil dos acadêmicos em sala de aula no curso de Licenciatura em Educação Física, pode-se destacar diferentes pontos, tantos positivos - com maior predominância -, como também negativos. Quando se diz respeito às experiências e contribuições trazidas pelo PIBID, todos os 
professores afirmam que o programa proporciona esse benefício aos acadêmicos nele inseridos. Nesse sentido, o professor 04 (18/12/2014) comenta que o PIBID "é uma forma de estruturar, de montar, de o aluno ter que trabalhar com planejamento, fazer relações teóricopráticas, propor novas atividades, buscar novos conhecimentos para quebrar aquele paradigma da escola de trabalhar sempre com as mesmas atividades". Concordando com a fala do docente 04, Pimenta (2004) afirma que as vivências têm um papel fundamental como ponto de partida do conhecimento durante a formação inicial, pois, de acordo com Tardif (2012), a prática é um recinto de aplicação da teoria, de produção, de transformação e de mobilização de saberes (teorias e conhecimentos). Assim sendo, pode-se inferir que a prática, durante o período de graduação, concebe experiências e contribuições essenciais para a compreensão do fazer docente, como ressalva o professor 06 (18/12/2014) no trecho de sua entrevista afirma:

Estar semanalmente em contato com a comunidade escolar, com a escola, ter tempo específico para o planejamento, reflexão sobre a prática, ter os momentos para se poder pensar mesmo no que tem sido feito enquanto estratégia didática, metodológica das sessões de aula, enriquece muito.

Tardif (2012) e Kleiman (2001) confirmam a fala do professor 06, pois, é através da aproximação entre os saberes iniciais e as práticas cotidianas que os docentes são levados a analisar, avaliar e ressignificar sua prática, sendo que essa prática reflexiva permite a construção de novos significados e a alteração da mesma de forma consciente. Sobre isso, Nóvoa (1997) corrobora que é por meio da reflexão crítica sobre as práticas e (re)construção de uma identidade pessoal que a formação se constrói, destacando-se o saber da experiência adquirida nessa trajetória percorrida. Dessa forma, fica evidente o crescimento do acadêmico como futuro docente, pois, com o PIBID, pode atuar e refletir constantemente sobre sua prática, corrigindo-a com o auxílio de colegas e professores.

Ao serem questionados se percebiam diferenças entre o perfil dos acadêmicos bolsistas e não bolsistas do PIBID, o docente 02 esboça de forma clara o que os demais professores relataram:

\footnotetext{
Me parece que se eu comparar esses acadêmicos com os demais sim, são extremamente mais comprometidos, mais organizados, têm uma possibilidade maior de seguir na carreira, de ter uma docência facilitada por esse primeiro contato [...] fica evidente que esses que escolhem esses caminhos, essas formações paralelas, têm um perfil bem diferente. Já são comprometidos, já tem uma visão de curso, uma visão de atuação diferenciada desde o primeiro semestre, então tudo que acontecer ao longo disso só vem somando aquilo que já havia apresentado, diferenciando como pessoa e acadêmico (Docente 02 - 16/12/2014).
}

Complementando com a fala do docente 02 , outros professores comentam que os acadêmicos que buscam esses projetos (como o PIBID, iniciação científica, extensão, etc.) já são acadêmicos diferenciados: "O acadêmico bolsista já está engajado, ele vê a importância de estar vinculado com a universidade, estar vinculado com os professores fora do período de sala de aula. [...] O aluno que se vincula a qualquer processo ele está na frente" (Docente 05 19/12/2014). "Acho que boa parte dos alunos que tem interesse no PIBID eles são alunos que de certo modo já estão interessados em se engajar. [...] Acho que, por vezes, o aluno que tem um perfil diferenciado procura esses projetos" (Docente 06 - 18/12/2014). Vale ressaltar outro ponto relevante do Programa: a participação de professores formados, sendo um o coordenador de área do PIBID (da Instituição de Ensino Superior - IES) e outro da escola pública de atuação (ambos da Educação Física). Os colaboradores, em suas entrevistas, afirmam que: "[...] o acadêmico que está no PIBID sim, ele demonstra essa postura de ser diferenciado, de ter essa organização e, por consequência, tendo um professor para guiar 
possibilita que eles vão estabelecer mais atividades de produção cientifica, então é uma consequência" (Docente 02 - 16/12/2014). "Ele tem o suporte do professor da Instituição de Ensino e tanto do professor da escola, que assume um compromisso de acompanhar esse aluno e que de fato acompanha" (Docente 03 - 16/12/2014). Portanto, o bolsista tem uma estrutura, formada por esses dois docentes, que os auxiliam no desenvolvimento das atividades escolares e, também, acadêmicas exigidas pelo Programa.

Em vista disso, o acadêmico tem a possibilidade de um crescimento superior quando comparado aos demais, visto que possui o auxilio do professor orientador, da Instituição de Ensino Superior e do professor supervisor, da escola pública onde atua, que acompanha as atividades dos bolsistas no espaço escolar e tem o papel de coformador no processo de iniciação à docência, juntamente com o docente da universidade (ANDRÉ, 2012). Conforme o professor 03 (16/12/2014), existe também grande diferença do PIBID quando comparado ao estágio não obrigatório, principalmente pelo fato de não existir esse acompanhamento de profissionais de fato.

Em relação a essa procura do PIBID por parte de acadêmicos diferenciados, os professores trouxeram outra questão:

\begin{abstract}
Os que são selecionados..., têm muitas vagas, mas os iniciais sempre são aqueles destaques, que já têm esses atributos, ter uma boa escrita, participar das aulas, enfim, tem um domínio. E os outros, que não são tão destaque assim e acabam entrando porque tem um grande número de vagas, acabam se apropriando dessa necessidade ao longo do processo, alguns não mudam o comportamento, mas outros vão ter esse diferencial (Docente $04-18 / 12 / 2014)$. [...] o processo já seleciona bons alunos pra prática. Mas também não dá pra dizer porque são 20 vagas, não entra só o suprassumo. E, muitas das vezes, eu já vi aluno que se escorava nas cordas mudando a postura, conduzindo aula, assumindo responsabilidades e o PIBID realmente se transformou como um elemento de transformação pra alguns sujeitos (Docente 06 $18 / 12 / 2014)$.
\end{abstract}

Sendo assim, percebe-se que temos dois aspectos diferentes em relação aos acadêmicos que buscam o PIBID: primeiro, a grande parte dos acadêmicos que se inserem no Programa já são acadêmicos interessados, na sua formação em geral; segundo, ocorreram, de fato, mudanças na postura de alguns acadêmicos não tão engajados assim, a partir de seu ingresso no Programa. Além disso, esses acadêmicos passam a ter uma visão ampliada em relação à formação, bem como traz o professor 05 (19/12/2014) em sua fala: "E o que é legal de ouvir pelo menos é que os bolsistas eles acabam em vislumbrar possibilidades futuras, eu quero fazer pós, eu quero fazer mestrado, alguns de forma mais arrojada, eu quero dar aula no nível superior".

Essa possibilidade de vislumbrar oportunidades futuras é construída a partir de ensejos ocasionados no PIBID. O professor 05 relata (19/12/2014) que "já houve uma participação bem maior na Feira de Iniciação Científica com os alunos do PIBID, bem maior mesmo. Porque a Educação Física normalmente tinha seis trabalhos, cinco, seis, sete trabalhos, hoje já teve mais de doze, então dobrou." Sendo assim, fica evidente a articulação entre as oportunidades ali vivenciadas pelos bolsistas com o almejo de possibilidades posteriores à sua formação.

Além desses aspectos positivos já citados, o docente 03 (16/12/2014) pondera que "há uma relação custo benefício, o valor de bolsa que se tem é um valor monetário muito interessante, comparado à carga horária que o aluno desenvolve. Então, ele consegue ter maior liberdade para conjugar com outra atividade [...]”. De acordo com Paredes (2012), é relevante a concessão de bolsas para os estudantes de licenciatura com o intento de estimulálos a ingressar na carreira docente, permitindo a construção de uma identidade profissional desde o início do curso, que tem como objetivo maior diminuir a discrepância na formação e a 
desvalorização do trabalho do professor. Sendo assim, percebe-se a bolsa como um instrumento necessário para incentivar a participação do estudante em atividades e programas vinculados às instituições de ensino superior, pois possuem o acompanhamento adequado para o desenvolvimento de um futuro profissional, bem como tem o intento de diminuir a desistência e abandono da docência por falta de práticas construtivas.

Apesar disso, como a carga horária mensal é de 36 horas, o bolsista tem a liberdade de conjugar outras atividades junto com o PIBID, o que pode ocasionar algumas dificuldades, relatadas pelos professores 05 (19/12/2014): "alguns dos alunos que estão vinculados ao PIBID se sobrecarregam e acabam deixando as disciplinas um pouco" e 04 (18/12/2014) "o bolsista do PIBID tem muitas tarefas, é muito atarefado". Portanto, esse aluno, que já era diferenciado, acaba por assumir muitos compromissos e cair no senso comum, em função da variável tempo, conforme afirma o professor 04. Contudo, ao passar por essa experiência, talvez o aluno consiga administrar melhor seu tempo nos próximos semestres, relata o docente 05 .

O docente $03(16 / 12 / 2014)$ pondera que, "ao mesmo tempo em que promovem esse enriquecimento em que eles conseguem trabalhar em grupos, eu penso que numa futura atuação profissional pode ser um pouco frustrante em termos de que é diferente da realidade da Educação Física em sala de aula". Percebe-se, portanto, que a atuação do PIBID apresentase um pouco distorcida da realidade "em que tu tens um cronograma a ser cumprido, tu têm alunos que não estão interessados, tu vais atuar sozinho, tu tens uma série de dificuldades, que no projeto são compartilhados com o grupo" (Docente 3 - 16/12/2014). Esse fato, inexistente na prática real, é percebido como uma limitação do programa, mas também pode "servir como exemplo para possibilidades futuras e reflexões importantes sobre o tema docência no contexto atual" (DIEDER, et al., 2015, p.514).

Vê-se, portanto, o PIBID como um programa que vem trazendo bons resultados durante a graduação nas licenciaturas, contudo o docente 04 (18/12/2014) ressalta que

A gente sempre espera que os bolsistas PIBID consigam fazer depois de formado aquilo tudo que eles se motivaram, planejaram, desejaram ao longo da sua passagem pelo PIBID, que eles transformaram a escola com projetos, com ações, que eles continuem, que esse é o grande problema da formação, que é um discurso na hora da formação e, na hora da prática, acaba se perdendo, se diluindo.

Somente um docente relatou em sua entrevista o retorno e o entusiasmo dos bolsistas, juntamente com a criação de uma identidade: “[...] nós somos pibidianos. Criou-se uma identidade muito forte entre quem participa [...] é legal isso, a construção de identidades e a paixão que fortalece ainda mais pela Educação Física" (Docente 03 - 16/12/2014). Nesse sentido, de acordo com estudos de Silva (2014), no relatório publicado pela CAPES (2013), algumas Instituições de Ensino Superior participantes do projeto apontam alguns impactos identificados entre os docentes, dentre eles: a diminuição da evasão e a procura pelos cursos de licenciatura; reconhecimento de status na comunidade acadêmica e elevação da autoestima; formação mais comprometida com resultados educacionais; aumento no desempenho escolar dos alunos envolvidos; sinergia entre o programa PIBID e Prodocência.

Portanto, não basta que a universidade forme para o conhecimento, cabe a ela, principalmente, formar para a competência. No momento em que se busca desenvolver competências profissionais dos licenciados, os conhecimentos teóricos adquiridos durante o curso, apesar de imprescindíveis, pouco adiantarão se não puderem ser mobilizados, integrados e utilizados de maneira rápida e segura na resolução dos problemas reais e específicos, com os quais se defrontam no estágio e, mais à diante, ao longo da carreira docente (BRASIL, 2010). 
Sendo assim, através das entrevistas dos docentes e embasamentos teóricos, fica evidente a relevância do PIBID para todas as partes envolvidas: bolsistas, Instituição de Ensino Superior e escola pública; além de outras partes que são beneficiadas, como os professores das escolas e Universidades e os alunos atendidos no programa. Conforme o docente 06 (18/12/2014) "Eu acho que o PIBID é um programa que os alunos que se vinculam a esse programa eles saem com uma formação diferenciada". Conforme Dieder et al. (2015), o PIBID contempla todas as necessidades do professor (planejar, atuar e produzir cientificamente), bem como contribui para a formação dos bolsistas, tornando-os conscientes acerca da relevância do papel do professor na sociedade e sua capacidade de modificar a realidade dos educandos, independente dos obstáculos encarados. Sem dúvidas, o programa enriquece o caminho formativo dos bolsistas, que passam a se envolver com diversas atividades do universo acadêmico, além de desenvolverem habilidades essenciais à docência (REICHERT; MEINHARDT; LIMA, 2014).

\section{Considerações finais}

Em relação à visão dos docentes sobre a influência do PIBID na formação profissional dos acadêmicos inseridos no programa, pode-se concluir que os professores observam o PIBID como um programa que realiza um dos ensejos discutidos há muito tempo por grandes autores que falam sobre formação: aliar os recintos de formação (universidades) à realidade da prática docente (escolas), possibilitando vivências que permitem a articulação entre teoria e prática, construindo um caminho de erros e acertos na docência, o que proporcionará, ao bolsista, o gosto ou não por exercer a futura profissão.

Sobre a percepção dos docentes com relação ao perfil dos acadêmicos em sala de aula no curso de Licenciatura em Educação Física, ficou evidente que: grande parte dos acadêmicos que buscam esse Programa já são alunos diferenciados; o auxilio de professores vinculados ao PIBID agregará valores à sua formação; alguns acadêmicos obtiveram uma mudança na postura após o ingresso no Programa; houve a criação de identidade dos bolsistas inseridos no PIBID, destacando-se o entusiasmo desses acadêmicos em relação ao curso e permanência nele.

Algumas questões trazidas, que podem ser aprimoradas: a possível frustração depois de formado por não haver a docência coletiva vivenciada no programa (que pode servir de exemplo para a prática docente futura) e a facilidade de conjugar outras atividades em função da pequena carga horária, o que ocasiona a sobrecarga de grande parte dos bolsistas (que através da experiência podem administrar melhor seu tempo posteriormente).

Sendo assim, destaca-se a relevância do Programa no meio acadêmico, incentivando a docência e possibilitando uma formação diferenciada para os bolsistas, que passam também a vislumbrar possibilidades futuras. Espera-se que esses bolsistas do PIBID possam continuar com esse entusiasmo e essa vontade de mudar a realidade da Educação Básica depois de formados, bem como que esse Programa persista, apesar do período de crise e cortes do Governo Federal, podendo-se, assim, afirmar que vivemos em uma pátria educadora. Além disso, entende-se como necessária a continuidade e inclusão de novas investigações sobre a temática. 


\title{
THE PERCEPTION OF PHYSICAL EDUCATION PROFESSORS OF THE CONTRIBUTIONS FOSTERED BY PIBID IN THE LEARNING PROCESS OF ITS PARTICIPATING STUDENTS
}

\begin{abstract}
The present study aims to investigate the perception of Physical Education Professors from Feevale University (Rio Grande do Sul) in regards to the academic development of their intern students who were part of the PIBID project from 2012 to 2014. We adopted a qualitative and descriptive approach to the study, and the data of this study consists of semistructured interviews. Six professors contributed to this study. The importance of the referred program has become evident in the perception of Physical Education Professors, since it fosters the act of teaching and enables students to have access to a more thorough and complete learning experience, because it presents theory and practice as ultimately linked. This impacts on a student's liking for teaching - or not, as well as a change in the perspective and behavior on the participating student's part.
\end{abstract}

Keywords: Physical Education, Continuing Teacher Education, Teaching.

\section{LA PERCEPCIÓN DE LOS DOCENTES DEL CURSO DE EDUCACIÓN FÍSICA EN RELACIÓN A LAS CONTRIBUCIONES DEL PIBID EN LA FORMACIÓN DE LOS ACADÉMICOS BECARIOS DEL SUB PROYECTO EDUCACIÓN FÍSICA}

\section{Resumen}

El estudio tiene como objetivo investigar la percepción de los profesores del curso de Licenciatura en Educación Física de la Universidad Feevale (Rio Grande do Sul) sobre el desarrollo académico de los becarios del sub proyecto PIBID Educación Física, inseridos en el programa de 2012 a 2014. Se adopta el diseño de un estudio cualitativo descriptivo. El instrumento usado para la recolección de los datos fue una entrevista semiestructurada y se contó con la participación de seis docentes. En la percepción de los docentes participantes del estudio se destacó la importancia del programa en el medio académico, que fomenta la enseñanza y permite una formación diferenciada para los becarios mediante la vinculación de la teoría y la práctica, impactando en el gusto o no por la enseñanza y en el cambio de comportamiento de los académicos después del ingreso en el programa.

Palabras-clave: Educación Física. Educación continua. Enseñanza.

\section{Referências}

ANDRÉ, M. Políticas e programas de apoio aos professores iniciantes no Brasil. Cadernos de pesquisa. v. 42, n.145, jan./abr., 2012, p.112-129. Disponível em: <http://www.scielo.br/scielo.php?pid=S010015742012000100008\&script=sci_abstract\&tlng= pt> Acesso em: 13 out. 2014.

BARDIN, L. Análise de conteúdo. São Paulo: Edições 70, 2011.

BIRK, M. Do princípio da pesquisa qualitativa à coleta de dados: uma trajetória percorrida por todos os pesquisadores. IN: CAUDURO, M. T. (Org.). Investigação em Educaçãa Física e Esportes: um olhar pela pesquisa qualitativa. Novo Hamburgo: Feevale, 2004.

BRASIL. Decreto no. 7. 219, de 24 de junho de 2010, Programa Institucional de Bolsa de iniciação à docência - PIBID, 2010. 
BRASIL. MEC, Secretaria de Educação Fundamental, Referenciais para formação de Professores. Brasília. 1999.

BRASIL. Resolução No 466, do CNS/MS sobre Diretrizes e Normas Regulamentadoras de Pesquisa envolvendo seres humanos, de 12 de dezembro de 2012. Disponível em: <http://conselho.saude.gov.br/resolucoes/2012/Reso466.pdf> Acesso em: 18 abr. 2015.

BORGES, C. M. F. O professor de Educação Física e a construção do saber. 4.ed. Campinas, SP: Papirus, 2003.

CAUDURO, M. T. (Org.). Investigação em Educação Física e Esportes: um olhar pela pesquisa qualitativa. Novo Hamburgo: Feevale, 2004.

CUNHA, M. I. da: O campo da iniciação à docência como um desafio. UNISINOS, 2010. Disponível em: <http://33reuniao.anped.org.br/33encontro/app/webroot/files/file/Trabalhos\%20em\%20PDF/ GT04-6134--Int.pdf> Acesso em: 22 jan. 2015

DIEDER, J. A. et al. A contribuição do PIBID para a formação dos acadêmicos bolsistas da escola Jorge Ewaldo Koch. Fiep Bulletin, v. 85, Special Edition, Article II, 2015, p. 511-515.

GADOTTI, M. Boniteza de um sonho: ensinar e aprender com sentido. Novo Hamburgo: Feevale, 2003.

KLEIMAN, A. B. A formação do professor: perspectivas da linguística aplicada. Campinas, SP: Mercado de Letras, 2001.

LIBÂNEO, J. C. Adeus professor, adeus professora?: novas exigências educacionais e profissão docente. 13 ed. São Paulo: Cortez, 2011.

LÜDKE, M.; ANDRÉ, M. E. D. A. Pesquisa em educação: abordagens qualitativas. São Paulo, SP: E.P.U., 1986.

MARTINY, L. E.; GOMES-DA-SILVA, P. N. A transposição didática na educação física escolar: o caminho formativo dos professores em formação inicial. Revista Brasileira de Estudos Pedagógicos (online). Brasília, v.95, n.239, jan./abr. 2014, p.175-196. Disponível em: <http://www.scielo.br/pdf/rbeped/v95n239/a10v95n239.pdf> Acesso em: jan. 2015.

NEGRINE, A. Instrumentos de coleta de informações na pesquisa qualitativa. In: TRIVIÑOS, A. N. S; MOLINA NETO, V. (Org). A pesquisa qualitativa na Educação Física: alternativas metodológicas. 2 ed. Porto Alegre: Editora da UFRGS/Sulina, 2004.

NÓVOA, António. Os professores e a sua formação. 3. ed. Lisboa: Dom Quixote, 1997.

PAREDES, O. G. G.; GUIMARÃES, M. O. Compreensões e Significados sobre o PIBID. Química Nova na Escola. v. 34, n. 4, novembro 2012, p. 266-277.

PIMENTA, S, G. LIMA, M. S. L. Estágio e Docência. São Paulo, Cortez, 2004. - (Coleção docência em formação). Série Saberes pedagógicos. 
POSSEBON, M. O estudo de caso na investigação em Educação Física na perspectiva qualitativa. In: CAUDURO, M. T. (Org). Investigação em Educação Física e Esportes: um olhar pela pesquisa qualitativa. Novo Hamburgo: Feevale, 2004.

PRODANOV, C. C.; FREITAS, E. C. Metodologia do trabalho científico: métodos e técnicas da pesquisa e do trabalho acadêmico. Novo Hamburgo, RS: Feevale, 2013.

REICHERT, I. C.; MEINHARDT, M; LIMA, B. F. A iniciação à docência na Feevale: Os primeiros passos de uma importante trajetória. In: REICHERT, C. I., Do dialogo entre escola e Universidade: O PIBID Feevale e seus primeiros passos e reflexões. Novo Hamburgo, RS, 2014.

Resolução no 03/2013. Reitoria da Universidade Feevale, 2013.

TARDIF, M. Saberes Docentes e formação profissional. 13. ed. Petrópolis, RJ: Vozes, 2012.

VEIGA, I. P. A. (Coord.). Repensando a didática. Campinas: Papirus, 1998.

Recebido em: 01/11/2015

Revisado em: 29/02/2016

Aprovado em: 21/06/2016

Endereço para correspondência:

janaina.dieder@gmail.com

Janaina Andretta Dieder

Instituição Evangélica de Novo Hamburgo, Fundação Evangélica.

Rua Frederico Mentz

Vila Nova

93525-360 - Novo Hamburgo, RS - Brasil 